Revista Brasileira de Odontologia Legal - RBOL

Odontologia Legal

\title{
PUBLICIDADE ODONTOLÓGICA NA INTERNET: OS SITES DE COMPRA COLETIVA
}

\section{Dental advertising on the Internet: collective purchase sites}

\author{
Wender Henrique Teles de OLIVEIRA*, Mauro Machado do PRADO**, Rhonan \\ Ferreira da SILVA ${ }^{* \star *}$ \\ * Acadêmico de Odontologia da Faculdade de Odontologia da Universidade Federal de Goiás; \\ ** Cirurgião-Dentista e Advogado, Professor Adjunto das Disciplinas de Bioética, Odontologia Legal e Orientação \\ Profissional da Faculdade de Odontologia da Universidade Federal de Goiás; \\ *** Cirurgião-Dentista e Perito Criminal da Superintendência de Polícia Técnico-Científica do Estado de Goiás, Professor \\ Adjunto das Disciplinas de Bioética, Odontologia Legal e Orientação Profissional da Faculdade de Odontologia da \\ Universidade Federal de Goiás.
}

\author{
Informação sobre artigo \\ Recebido: 04 Set 2012 \\ Recebido corrigido: 27 Abr 2013 \\ Aceito em: 23 Abr 2014
}

\author{
Autor para correspondência \\ Wender Henrique Teles de Oliveira \\ Rua 231, Quadra 72, Lote 08, Residencial Barros II - Casa 1, \\ Setor Leste Vila Nova. CEP: 74.640-220. Goiânia - Goiás.
}

\section{RESUMO}

O presente trabalho consiste em um estudo descritivo-analítico de publicidades odontológicas veiculadas em sites de compra coletiva, com o objetivo de classificar as publicidades de acordo com região, estado e tipos de produtos e serviços ofertados, e confrontar a forma e o conteúdo de sua divulgação com os preceitos éticos e legais vigentes. Fez-se revisão de literatura e emprego da Técnica da Análise de Conteúdo quando da interpretação de cada publicidade componente da amostra e das proposições emanadas de corpo de normas éticas e legais direta ou indiretamente relacionadas à regulamentação da Odontologia no Brasil. A região Sudeste apresentou a maior quantidade total de ofertas $(68,30 \%)$, seguida pelas regiões Nordeste $(10,97 \%)$ e Sul (10,36\%); o estado de São Paulo apresentou um maior número de ofertas $(44,51 \%)$, seguido pelo Rio de Janeiro (18,29\%) e Minas Gerais $(5,48 \%)$; quanto aos serviços ofertados, as promoções ofereceram, principalmente, clareamento dental, profilaxia/limpeza, avaliação odontológica e aplicação de flúor; em relação aos produtos, foram ofertados gel clareador e Plano de Saúde. Identificou-se que as publicidades analisadas violam os preceitos éticos vigentes, a legislação que regulamenta a Odontologia no país e as normas consumeristas, implicando em concorrência desleal e prática comercial de risco para a saúde da população.

\section{PALAVRAS-CHAVE}

Anúncios, Internet, Ética Odontológica, Legislação Odontológica, Defesa do Consumidor.

\section{INTRODUÇÃO}

\section{O exercício legal da Odontologia}

O exercício lícito da Odontologia

\section{no Brasil envolve capacitação}

acadêmica ou técnica, a depender da categoria. E para que possa ser exercida, é necessário o regular registro e inscrição na autarquia pública fiscalizadora, em seus âmbitos federal (Conselho Federal de 
Odontologia - CFO) e estadual etc).

(Conselho Regional de Odontologia CRO) ${ }^{1}$.

A Lei de $n^{0} 5.081$, de 24 de agosto de $1966^{1}$, regulamenta o exercício da Odontologia no país, atribuindo competências ao Cirurgião-dentista. Para o Técnico em Prótese Dentária (TPD), deve ser observada a Lei de ํㅡ $6.710^{2}$, de 5 de novembro de 1979. Em 24 de dezembro de 2008, houve regulamentação das profissões de Técnico em Saúde Bucal (TSB) e de Auxiliar em Saúde Bucal (ASB), por meio da Lei de no $11.889^{3}$. Por fim, das cinco categorias profissionais da Odontologia, apenas o Auxiliar de Prótese Dentária (APD) tem sua prática regulamentada por Resolução do CFO, de № 063, de 8 de abril de $2005^{4}$.

Além das leis citadas acima, devem ser conhecidas e seguidas outras de aplicação direta, como a Constituição da República Federativa do Brasil (Carta Magna de 1988) ${ }^{5}$, o Código Civil (Lei de № 10.406, de 10 de janeiro de 2002) ${ }^{6}$, o Código Penal (Decreto-Lei de o 2.848, de 7 de dezembro de 1940$)^{7}$ e o Código de Defesa do Consumidor (Lei de no 8.078, de 11 de setembro de 1990) ${ }^{8}$, dentre outras (Estatuto da Criança e do Adolescente ${ }^{9}$, Estatuto do Idoso ${ }^{10}$,

Assim, o profissional da Odontologia deve observar a legislação específica de cada categoria, a legislação aplicada e as normas deontológicas ditadas pelo Conselho Federal de Odontologia.

\section{A ética profissional}

Dentre as resoluções de cunho deontológico, são peças de consulta obrigatória: o Código de Ética Odontológica $(\mathrm{CEO})^{11}$, que tem como finalidade orientar os profissionais e entidades odontológicas quanto aos seus direitos e deveres relacionados com relação interprofissional, sigilo, pesquisa, publicidade, entre outros; e - Código de Processo Ético Odontológico $(\mathrm{CPEO})^{12}$, que estabelece 0 rito processual caso 0 profissional ou entidade não siga as premissas do CEO, podendo o mesmo ser responsabilizado e punindo eticamente.

No que diz respeito às esferas de avaliação da responsabilidade profissional, tem-se, dentre elas, a ético-disciplinar, que representa avaliação de conduta preconizada como adequada por parte de um profissional liberal para o exercício de sua atividade. A observação dos valores adotados por uma determinada categoria para a prática responsável e idônea é aplicável a 
todos os pares, e acompanhada pelo órgão fiscalizador da referida profissão $^{11}$.

\section{A publicidade em Odontologia}

Um dos motivos mais ensejadores de processos éticos em desfavor de Cirurgiões-dentistas é a publicidade odontológica. Principalmente, nos tempos atuais, dada a prática de divulgação por meio eletrônico, em especial, aquelas envolvendo vendas de produtos e serviços em sites de compra coletiva. Este tipo de divulgação dos serviços odontológicos tem sido objeto de análise e preocupação pelos Conselhos Federal e Regionais de Odontologia, quanto a incorrerem tais divulgações em prática ilegal e antiética $^{13}$.

Os sites de compra coletiva iniciaram em 2008, com a criação do Groupon, pelo estadunidense Andrew Manson. No Brasil, a criação foi no início de 2010 com o Peixe Urbano, por Júlio Vasconcelos. A concorrência desse mercado no país está crescendo significativamente, com o surgimento de pelo menos dois novos sites de compras coletivas por mês ${ }^{14}$.

As compras coletivas consistem em um modelo de comércio eletrônico, cujo principal objetivo é promover grandes descontos, nos mais variados estabelecimentos comerciais espalhados por todo 0 território nacional, ou mesmo em outros países. É necessário que um número mínimo de clientes seja atingido, em um prazo estipulado pelo site, para a ativação da oferta. Assim, os interessados recebem um cupom virtual (voucher), normalmente enviado por e-mail, o qual permite que o cliente comprove a compra e ganhe o desconto na loja ${ }^{14}$.

Tendo em vista as crescentes iniciativas e formas de divulgação de prestações de serviços por meio de sites, inclusive envolvendo a prática odontológica, importa uma análise desta nova modalidade de publicidade e seu confronto com as normas e princípios que regem o exercício da Odontologia no Brasil, com o objetivo de evitar a exposição da profissão e da sociedade a situações de concorrência desleal e de risco para a própria saúde do consumidor.

Neste contexto, o presente artigo tem como objeto e proposição o levantamento e a análise de publicidades envolvendo produtos e serviços odontológicos em sites de compra coletiva com ofertas válidas para o território brasileiro, de modo a 
identificar conteúdos e violações a preceitos legais e éticos.

\section{MATERIAL E MÉTODO}

Este estudo compreendeu os seguintes

procedimentos metodológicos:

1. Seleção de amostra de sites de compra coletiva, utilizando o portal

\section{WWW.BOLSADEOFERTAS.CO}

M.BR, uma vez que este endereço eletrônico reúne notícias, bem como a listagem de todos os sites de compra coletiva de circulação nacional;

2. Identificação de sites de compra coletiva com veiculação de publicidade odontológica;

3.

Análise de conteúdo de cada publicidade;

4.

Classificação por região, estado e tipos de produtos e serviços;

5. Confronto com a prescrição legal e ética.

A pesquisa consistiu em levantamento inicial de sites de compra coletiva, por um único pesquisador, entre os meses de abril e agosto de 2011. Foi pesquisada em toda a base de dados cadastrada no BOLSADEOFERTAS ${ }^{15}$, a qual era composta por 246 sites de compra coletiva que foram analisados para a seleção daqueles que apresentavam publicidades relacionadas com serviços e produtos odontológicos.

Em seguida, as referidas publicidades odontológicas foram classificadas de acordo com: a região do país, o estado e os tipos específicos de produtos e serviços veiculados.

Passou-se à análise de cada uma das publicidades pela técnica da Análise de Conteúdo, com vistas ao confronto entre o que é permitido por lei e pelas normas deontológicas e o que efetivamente foi ofertado.

A Análise de Conteúdo é descrita por Bardin (1977) ${ }^{16}$ como um conjunto de técnicas de análise das comunicações, que utiliza procedimentos sistemáticos e objetivos de descrição do conteúdo das mensagens, visando obter indicadores (quantitativos ou não) que possibilitem a inferência de conhecimentos relativos às condições de produção e recepção dessas mensagens. No presente estudo, foi trabalhada a análise temática, em suas três fases: a préanálise; a exploração do material/corpo de textos; a inferência e interpretação dos dados.

\section{RESULTADOS}

Identificação de sites de compra coletiva com veiculação de publicidade odontológica e seus 
respectivos conteúdos:

A lista do BOLSADEOFERTAS continha 246 sites, tendo sido encontradas 164 publicidades odontológicas em 54 destes (21,95\%).

$\mathrm{Na}$ Tabela 1, observa-se que a região Sudeste foi a que apresentou a maior quantidade total de ofertas, $112(68,30 \%)$, seguida pelas regiões Nordeste $(18$ - 10,97\%) e Sul (17 $10,36 \%$ ). Por sua vez, a Tabela 2 , que mostra a distribuição do número de ofertas de acordo com o estado, evidencia que São Paulo apresenta um maior número de ofertas (73 $44,51 \%$ ), seguido pelo Rio de Janeiro $(30-18,29 \%)$ e Minas Gerais (9 $5,48 \%)$.

A variável "Apenas site", encontrada em ambas as tabelas, traduz a venda de produtos sem 0 intermédio de um Cirurgião-dentista ou de alguma empresa, ou seja, o pedido do produto era feito direto pelo site e o cliente o recebia pelo correio.

Quanto aos serviços ofertados, nota-se, na Tabela 3, que as promoções oferecem, principalmente: clareamento dental (140), profilaxia/limpeza (114), avaliação odontológica (60) e aplicação de flúor (54). Em relação aos produtos, foram ofertados Plano de Saúde (3) e gel clareador, este vendido diretamente pela empresa ou pelo site (12).

\section{DISCUSSÃO}

Segundo o Conselho Federal de Odontologia (CFO), no Brasil, existem 251.981 Cirurgiões-dentistas em atividade. Destes, 77.545 estão localizados no estado de São Paulo; 29.892, em Minas Gerais; e 28.854, no Rio de Janeiro ${ }^{17}$. Evidenciando, então, que a região Sudeste possui o maior número de profissionais no país, o que justifica a quantidade de publicidade odontológica (Tabela 1). Fato este, confirmado, também, na Tabela 2, em relação aos Estados que mais ofertam produtos e serviços odontológicos, como clareamento, profilaxia, avaliação, etc.

No que diz respeito aos resultados obtidos na Tabela 3 , observa-se que o clareamento dental é o serviço mais ofertado, haja vista que existe um maior interesse dos pacientes com relação a este procedimento, devido a uma intensa pressão da sociedade em torno do "sorriso branco" como padrão de beleza $^{18}$. 
Oliveira WHT, Prado MM, Silva RF

Tabela 1 - Classificação das publicidades odontológicas de acordo com a região.

\begin{tabular}{cccc}
\hline Região & Serviços & Produtos & Total de ofertas (\%) \\
\hline Sudeste & 102 & 10 & $112(68,30)$ \\
Nordeste & 15 & 3 & $18(10,97)$ \\
Sul & 17 & - & $17(10,36)$ \\
Centro-Oeste & 13 & - & $13(7,93)$ \\
Norte & 2 & - & $2(1,22)$ \\
Apenas site & - & 2 & $2(1,22)$ \\
Total & 149 & 15 & $164(100)$ \\
\hline
\end{tabular}

Tabela 2 - Classificação das publicidades odontológicas de acordo com o estado

\begin{tabular}{|c|c|c|c|}
\hline Estado & Serviços & Produtos & Total de ofertas (\%) \\
\hline São Paulo & 65 & 8 & $73(44,51)$ \\
\hline Rio de Janeiro & 29 & 1 & $30(18,29)$ \\
\hline Minas Gerais & 8 & 1 & $9(5,48)$ \\
\hline Paraná & 8 & - & $8(4,88)$ \\
\hline Rio Grande do Sul & 5 & - & $5(3,05)$ \\
\hline Distrito Federal & 5 & - & $5(3,05)$ \\
\hline Goiás & 4 & - & $4(2,44)$ \\
\hline Mato Grosso do Sul & 4 & - & $4(2,44)$ \\
\hline Santa Catarina & 4 & - & $4(2,44)$ \\
\hline Sergipe & 3 & - & $3(1,83)$ \\
\hline Alagoas & 2 & - & $2(1,22)$ \\
\hline Bahia & 2 & 1 & $3(1,83)$ \\
\hline Maranhão & 2 & - & $2(1,22)$ \\
\hline Pernambuco & 2 & 1 & $3(1,83)$ \\
\hline Rio Grande do Norte & 2 & - & $2(1,22)$ \\
\hline Roraima & 2 & - & $2(1,22)$ \\
\hline Ceará & 1 & 1 & $2(1,22)$ \\
\hline Paraíba & 1 & - & $1(0,61)$ \\
\hline Apenas site & - & 2 & $2(1,22)$ \\
\hline Total & 149 & 15 & 164 \\
\hline
\end{tabular}


Tabela 3 - Tipos específicos de produtos e serviços veiculados

\begin{tabular}{|c|c|c|}
\hline Ofertas & & Quantidade \\
\hline \multirow[t]{21}{*}{ Serviços } & Clareamento dental & 140 \\
\hline & Profilaxia/Limpeza & 114 \\
\hline & Avaliação Odontológica & 60 \\
\hline & Aplicação de Flúor & 54 \\
\hline & Jato de Bicarbonato & 10 \\
\hline & Dessensibilização/Laserterapia & 8 \\
\hline & Moldeiras & 6 \\
\hline & Gel clareador (oferecido pelo dentista) & 5 \\
\hline & Avaliação Ortodôntica & 4 \\
\hline & Colocação de aparelho fixo & 3 \\
\hline & Documentação Ortodôntica & 2 \\
\hline & Restauração & 2 \\
\hline & Polimento dentário & 2 \\
\hline & Orientação de higiene bucal & 1 \\
\hline & Orçamento & 1 \\
\hline & Diagnóstico por imagem & 1 \\
\hline & Exame Clínico & 1 \\
\hline & Diagnóstico & 1 \\
\hline & Piercing & 1 \\
\hline & Manutenção Ortodôntica & 1 \\
\hline & Total & 417 \\
\hline \multirow[t]{3}{*}{ Produtos } & Gel clareador (vendido pela empresa/no site) & 12 \\
\hline & Plano de saúde & 3 \\
\hline & Total & 15 \\
\hline Total & & 432 \\
\hline
\end{tabular}

Confronto com as prescrições legal e ética

$\mathrm{Na}$ Lei 5.081/66, Artigo 7º, alíneas "a" e "g", observa-se que ao Cirurgião-dentista é vedado, respectivamente, "expor em público trabalhos odontológicos e usar de artifícios de propaganda para granjear clientela" e "anunciar preços de serviços, modalidades de pagamento e outras formas de comercialização da clínica que signifiquem competição desleal". Assim, as publicidades veiculadas nos sites que compõem a amostra analisada, em sua totalidade, afrontam vedação legal de anúncio de desconto e/ou modalidade de pagamento, bem como exposição pública de procedimentos odontológicos de forma a representar competição desleal e aliciamento de pacientes ${ }^{1}$.

O Capítulo XVI do Código de Ética 
Odontológica (CEO) ${ }^{11}$ vigente trata da comunicação e da divulgação em Odontologia. Neste capítulo, tem-se disciplinados o anúncio, a propaganda e a publicidade. Esta norma deontológica explicita claramente como fazer uma correta publicidade: 0 que deve ser contemplado, o que pode e o que não pode esta conter ${ }^{11}$.

As faltas éticas encontradas nas publicidades analisadas podem ser tipificadas, em especial, nos seguintes artigos:

Art. 32. Constitui infração ética: I. apregoar vantagens irreais visando a estabelecer concorrência com entidades congêneres;

VIII. oferecer serviços profissionais como bonificação em concursos, sorteios, premiações e promoções de qualquer natureza;

Art. 44. Constitui infração ética:

I. fazer publicidade e propaganda enganosa, abusiva, inclusive com expressões ou imagens de antes e depois, com preços, serviços gratuitos, modalidades de pagamento, ou outras formas que impliquem comercialização da Odontologia ou contrarie o disposto neste Código;

VII. aliciar pacientes, praticando ou permitindo a oferta de serviços através de informação ou anúncio falso, irregular, ilícito ou imoral, com o intuito de atrair clientela, ou outros atos que caracterizem concorrência desleal ou aviltamento da profissão, especialmente a utilização da expressão "popular";

X. anunciar serviços profissionais como prêmio em concurso de qualquer natureza ou através de aquisição de outros bens pela utilização de serviços prestados; XII. expor ao público leigo artifícios de propaganda, com o intuito de granjear clientela, especialmente a utilização de imagens e/ou expressões antes, durante e depois, relativas a procedimentos odontológicos; XIII. participar de programas de comercialização coletiva oferecendo serviços nos veículos de comunicação;

e,

XIV. realizar a divulgação e oferecer serviços odontológicos com finalidade mercantil e de aliciamento de pacientes, através de cartão de descontos, caderno de descontos, mala direta via internet, sites promocionais ou de compras coletivas, telemarketing ativo à população em geral, stands promocionais, caixas de som portáteis ou em veículos automotores, plaqueteiros entre outros meios que caracterizem concorrência desleal e desvalorização da profissão ${ }^{11}$.

Deve ser ressaltado que, conforme 0 Artigo 45, pela publicidade e propaganda em desacordo com as normas estabelecidas no CEO, respondem 
solidariamente os proprietários, responsável técnico e demais profissionais que tenham concorrido para a infração, na medida de sua culpabilidade ${ }^{11}$.

As penalidades previstas no CEO $^{11}$ vão, gradativamente, de advertência confidencial (em aviso reservado), censura confidencial (em aviso reservado), censura pública (em publicação oficial), suspensão do exercício profissional por até 30 dias, à cassação do exercício pelo CFO - Artigos 51 a 57. Existe, entretanto, a possibilidade de ocorrência de manifesta gravidade quando: da veiculação de propaganda ilegal (Artigo 53, Inciso VII), houver oferta de serviços odontológicos de forma abusiva, enganosa imoral ou ilegal (Artigo 53, Inciso XI); e, especificamente, forem ofertados serviços odontológicos em sites de compras coletivas ou similares (Artigo 53, Inciso XII) ${ }^{11}$.

Em 1990, o Brasil passou a contar com o Código de Defesa do Consumidor (CDC), Lei Federal que veio disciplinar as relações de consumo, estabelecendo normas de ordem pública e interesse social voltadas para a proteção e defesa do consumidor de produtos $\mathrm{e}$ serviços ${ }^{8}$.
A atividade profissional de prestação de serviços de atenção à saúde nesta legislação se viu contemplada, devendo o Cirurgiãodentista ater-se à Política Nacional de Relações de Consumo e aos Direitos Básicos do Consumidor ${ }^{8}$.

Quanto à Política Nacional de Relações de Consumo, importa destacar os seguintes princípios: de reconhecimento da vulnerabilidade do consumidor (não tem informações técnicas); de ação governamental no sentido de garantia dos produtos e serviços com padrões adequados de qualidade, segurança durabilidade e desempenho; e de coibição e repressão de abusos ${ }^{8}$.

Dentre os Direitos Básicos do Consumidor, destacam-se: a proteção da vida, da saúde e da segurança; informação adequada e clara sobre os diferentes produtos e serviços; a proteção contra publicidade enganosa e abusiva; a efetiva prevenção e reparação de danos patrimoniais e morais; e a facilitação da defesa de seus direitos, inclusive com a inversão do ônus da prova em favor do consumidor, quando o juiz entender verdadeira sua alegação ou ser ele hipossuficiente (ausência de informações a respeito dos produtos 
e serviços que adquire - em relação à técnica odontológica, por exemplo) ${ }^{8}$.

Quanto à responsabilidade pelos serviços prestados, o CDC adotou, como regra geral, a teoria da responsabilidade objetiva, ou do risco da atividade, com culpa presumida. Contudo, previu exceção para os profissionais liberais, cuja responsabilidade pessoal deverá ser apurada mediante a verificação de culpa (negligência, imprudência ou imperícia) - Artigo 14, parágrafo 4ํํ용. Quando das práticas comerciais, não se pode deixar de observar aspectos legais relacionados à oferta e à publicidade. O Artigo 31 disciplina que "A oferta e apresentação de produtos ou serviços devem assegurar informações corretas, claras, precisas, ostensivas e em língua portuguesa sobre suas características, qualidades, quantidade, composição, preço, garantia, prazos de validade e origem, entre outros dados, bem como sobre os riscos que apresentam à saúde e segurança dos consumidores." Diante desta norma, percebe-se que os profissionais da área da saúde têm a árdua tarefa de contemplar tais aspectos, associado ao fato de ainda ter que observar os preceitos deontológicos do CEO, que, muitas vezes, entram em conflito com a norma consumerista ${ }^{8}$.

A publicidade deve ser veiculada de tal forma que 0 consumidor não seja levado a engano ou induzido a se comportar de forma prejudicial ou perigosa à sua saúde ou segurança, conforme preceitua o artigo abaixo:

Art. 37. É proibida toda publicidade enganosa ou abusiva.

$\S 1^{\circ}$ É enganosa qualquer modalidade de informação ou comunicação de caráter publicitário, inteira ou parcialmente falsa, ou, por qualquer outro modo, mesmo por omissão, capaz de induzir em erro o consumidor a respeito da natureza, características, qualidade, quantidade, propriedades, origem, preço e quaisquer outros dados sobre produtos e serviços.

$\S 2^{\circ}$ É abusiva, dentre outras, a publicidade discriminatória de qualquer natureza, a que incite à violência, explore o medo ou a superstição, se aproveite da deficiência de julgamento e experiência da criança, desrespeite valores ambientais, ou que seja capaz de induzir o consumidor a se comportar de forma prejudicial ou perigosa à sua saúde ou segurança ${ }^{8}$. As práticas comerciais veiculadas nos sites analisados 
podem incorrer, de uma forma ou de outra, em práticas consideradas abusivas, o que não pôde ser efetivamente verificado no presente estudo, por depender de análise da efetiva prestação do serviço ou entrega do produto.

Como a venda de produtos e serviços por meio dos sites de compra coletiva analisados carece de pactuação contratual específica, detalhada, pormenorizada, há também que ser considerado 0 aspecto de proteção contratual previsto no CDC. Ou seja, as cláusulas contratuais serão interpretadas de maneira mais favorável ao consumidor. E estas sequer existem nas pactuações em sites de compra coletiva, salvo pelo conteúdo da oferta, que obriga o fornecedor.

Outro fator a ser discutido consiste nas garantias por vezes ofertadas, remetendo a obrigações de resultado que invariavelmente gerarão responsabilização do profissional em situações de não atendimento das expectativas do consumidor. O clareamento é exemplo contundente de que o paciente pode não ficar satisfeito com o resultado obtido e questionar sua oferta com fotografias associadas a expressões, por exemplo, de "antes, durante e depois", que inclusive representam proibição pelo CEO - Artigo 44, Inciso XII ${ }^{11}$.

Percebe-se que a legislação específica que regulamenta a prática da Odontologia no país é expressamente restritiva quanto a aspectos que são, ao contrário, dispostos como obrigatórios na prática consumerista brasileira. Salienta-se a vedação legal específica ao Cirurgião-dentista de anunciar publicamente gratuidade e preços de serviços ou mesmo formas de pagamento, bem como haver proibição de exposição pública de trabalhos ou do uso de artifícios de propaganda que venham a aliciar clientela e, consequentemente, resultar em competição desleal para com os seus pares. Por outro lado, o Código de Defesa do Consumidor preconiza, e até exige, a prática de anúncios ou publicidades com ostensiva informação, ou seja, para esta norma, preços, descontos ou modalidades de pagamento, por exemplo, devem estar claramente demonstrados na oferta. Entendese, portanto, haver conflito entre as citadas leis. Sendo recomendado ao Cirurgião-dentista que, em âmbito de pactuação de serviços, sejam 
observados os preceitos da Lei do Consumidor, mas que, em divulgações públicas, abstenha-se de ferir o que aparece proibido na lei específica que regulamenta 0 exercício da Odontologia no país e nas normas deontológicas vigentes.

\section{CONCLUSÃO}

A partir do levantamento e análise da amostra de publicidades odontológicas veiculadas em sites de compra coletiva, identificou-se que estas violam preceitos legais $\mathrm{e}$ éticos vigentes, ferindo o que é proibido pela legislação que regulamenta a Odontologia no país, em desrespeito à política nacional e princípios orientadores das relações de consumo de produtos e serviços, bem como apresentam-se em desacordo com os preceitos éticos adotados para a prática odontológica digna e responsável. Em especial, por poderem ser interpretadas como propagandas enganosas ou abusivas e por veicularem conteúdos com oferta explícita de preços, descontos e modalidades de pagamento.

Ainda, as publicidades, objeto de análise no presente estudo, remetem: à divulgação do exercício profissional em concorrência desleal com os pares, pelas promoções que induzem a aliciamento de pacientes; a uma prática comercial desrespeitosa para com a população consumidora de produtos e serviços, em que pese a necessidade de avaliação clínica individualizada e o conteúdo e forma das informações prestadas; e a um potencial risco de conflitos de interesses e responsabilização para o próprio profissional anunciante, por criarem expectativas que, mais das vezes, incidem em obrigação de resultado e podem frustrar as expectativas dos consumidores.

Em específico, a região Sudeste foi a que apresentou a maior quantidade total de ofertas, o que pode ser justificado pela concentração de profissionais da Odontologia nesta. O clareamento dental representou o serviço e o produto mais promovido e ofertado, remetendo à preocupação estética como atrativo para a população consumidora. 


\section{ABSTRACT}

The present work consists in a descriptive and analytical study of dental advertisements available in collective buying websites and aims to classify the advertisements according to the region, state and types of products and services offered, and to compare the form and contents with the current ethical and legal precepts. The study consisted in literature review and use of the Technique of Content Analysis for the interpretation of each advertisement of the sample and of the proposals emanated from the body of ethical and legal norms directly or indirectly related to the regulation of dentistry in Brazil. The Southeast region was the one with the largest total amount of bids $(68.30 \%)$, followed by Northeast (10.97\%) and South (10.36\%); the state of São Paulo had a greater number of bids $(44.51 \%)$, followed by Rio de Janeiro $(18.29 \%)$ and Minas Gerais $(5.48 \%)$; considering the services, specials offers mainly involved tooth whitening, prophylaxis/cleaning, dental evaluation and application of fluoride; the products offered were whitening gel and Health Plan. It was identified that the advertisements analyzed infringe the actual ethical precepts, the laws directly related to dental practice in Brazil, and also the rules that protect consumers' rights, resulting in unfair competition and trade practice of risk to the health of the population.

\section{KEYWORDS}

Advertisements, Internet, Dental Ethics, Dental Legislation, Consumer Advocacy

\section{REFERÊNCIAS}

1. BRASIL. Lei de no 5.081 , de 24 de agosto de 1966. Regula o exercício da Odontologia no país.

2. BRASIL. Lei de no 6.710 , de 5 de novembro de 1979. Dispõe sobre a profissão de Técnico em Prótese Dentária e determina outras providências.

3. BRASIL. Lei de $n^{\circ} 11.889$, de 24 de dezembro de 2008. Regulamenta o exercício das profissões de Técnico em Saúde Bucal - TSB e de Auxiliar em Saúde Bucal - ASB

4. BRASIL. Conselho Federal de Odontologia. Resolução de $n^{0}$ 63, de 19 de abril de 2005. Aprova a Consolidação das Normas para Procedimentos nos Conselhos de Odontologia.

5. BRASIL. Constituição da República Federativa do Brasil, de 5 de outubro de 1988.

6. BRASIL. Lei de $n^{\circ} 10.406$, de 10 de janeiro de 2002. Institui o Código Civil.
7. BRASIL. Decreto-Lei de o 2.848, de 7 de dezembro de 1940. Código Penal.

8. BRASIL. Lei de $n^{\circ} 8.078$, de 11 de setembro de 1990 . Dispõe sobre a proteção do consumidor e dá outras providências.

9. BRASIL. Lei de $n^{\circ} 8.069$, de 13 de julho de 1990. Dispõe sobre o Estatuto da Criança e do Adolescente e dá outras providências.

10. BRASIL. Lei de 10.741 , de $1^{\circ}$ de outubro de 2003. Dispõe sobre o Estatuto do Idoso e dá outras providências.

11. BRASIL. Conselho Federal de Odontologia. Resolução de no 118 , de 11 de maio de 2012. Código de Ética Odontológica.

12. BRASIL. Conselho Federal de Odontologia. Resolução de $n^{\circ} \quad 59$, de 21 de setembro de 2004. Código de Processo Ético Odontológico. 
13. BRASIL. Conselho Federal de Odontologia. Jornal do Conselho Federal de Odontologia, Ano 18, no 98, jan-fev-mar, 2011.

14. LOPES LUT. Inovação e consumo: compras coletivas pela Internet [Monografia]. Brasília: Universidade de Brasília; 2011.

15. BOLSA DE OFERTAS. Brasil: Mercado de Compra Coletiva já tem 246 sites no Brasil. Disponível em: http://www.bolsadeofertas.com.br.
16. BARDIN L. Análise de Conteúdo. Lisboa: Edições 70; 1977.

17. BRASIL. Conselho Federal de Odontologia. Totalização geral dos inscritos em atividade no Brasil, jan, 2013.

18. PORTOLANI JUNIOR MV, CANDIDO MSM. Efeito dos agentes clareadores sobre as estruturas dentais. Revista de Odontologia da UNESP. 2005; 34(2): 91-4. 